\title{
Stable calcium isotope fractionation during chemical weathering.
}

\author{
UTPALENDU HALDAR ${ }^{1}$, RAMANANDA CHAKRABARTI ${ }^{2}$ \\ AND ROBERTA L. RUDNICK ${ }^{3}$ \\ ${ }^{1}$ Indian Institute of Science \\ ${ }^{2}$ Indian Institute of Science, Bangalore \\ ${ }^{3}$ University of California at Santa Barbara \\ Presenting Author: utpalenduh@iisc.ac.in
}

The Cayce diabase saprolite in South Carolina is wellcharacterized in terms of its geochemical and isotopic compositions and provides insights into the effects of chemical weathering [1-3]. Here, we report preliminary stable $\mathrm{Ca}$ isotope data, measured using double spike $\left({ }^{43} \mathrm{Ca}-{ }^{48} \mathrm{Ca}\right)$ TIMS (Thermo Scientific, Triton Plus), at the Centre for Earth Sciences, IISc, Bangalore, to understand the behaviour of $\mathrm{Ca}$ isotopes during continental weathering. The saprolite samples $(\mathrm{n}=10)$ show wide variability in $\delta^{44 / 40} \mathrm{Ca}_{\mathrm{SRM} 915 \mathrm{a}}$ values which range from $0.96 \%$ o $( \pm 0.13,2 \mathrm{SD})$ in the unweathered parent rock to $1.26 \%$ o $( \pm 0.10,2 \mathrm{SD})$. The $\delta^{44 / 40} \mathrm{Ca}$ values positively correlate with Chemical Index of Alteration (CIA, 45-95) and negatively correlate with $\mathrm{Al}$ normalized $\mathrm{Ca}$ concentration and bulk density $\left(3-0.8 \mathrm{~g} / \mathrm{cm}^{3}\right)$. These trends indicate that the lighter isotopes of $\mathrm{Ca}$ are preferentially leached into the hydrosphere, driving the $\delta^{44 / 40} \mathrm{Ca}$ of the regolith to values higher than the unweathered parent rock. Additionally, the saprolite samples display a positive correlation between $\delta^{44 / 40} \mathrm{Ca}$ and $\delta^{26} \mathrm{Mg}$ and a negative correlation between $\delta^{44 / 40} \mathrm{Ca}$ and $\delta^{7} \mathrm{Li}$, indicating that some clay minerals preferentially take up the heavier isotopes of $\mathrm{Ca}$.

[1]. Gardner et al. (1981) Clays and Clay Minerals 29.3 : 184190. [2]. Rudnick et al. (2004) Chemical Geology 212.1-2 : 4557. [3]. Teng et al. (2010) Earth and Planetary Science Letters 300.1-2: 63-71. 